\title{
trabalnonecessário
}

issn: $1808-799 \mathrm{X}$

ano 4 - número 4 - 2006

\section{O PAPEL DO TRABALHO NA TRANSFORMAÇÃO DO MACACO EM HOMEM (1876)*}

Friederich Engels

O trabalho é a fonte de toda riqueza, afirmam os economistas. Assim é, com efeito, ao lado da natureza, encarregada de fornecer os materiais que ele converte em riqueza. $O$ trabalho, porém, é muitíssimo mais do que isso. É a condição básica e fundamental de toda a vida humana. E em tal grau que, até certo ponto, podemos afirmar que o trabalho criou o próprio homem.

Há muitas centenas de milhares de anos, numa época, ainda não estabelecida em definitivo, daquele período do desenvolvimento da Terra que os geólogos denominam terciário, provavelmente em fins desse período, $\left({ }^{1}\right)$ vivia em algum lugar da zona tropical talvez em um extenso continente hoje desaparecido nas profundezas do Oceano Indico uma raça de macacos antropomorfos extraordinariamente desenvolvida. Darwin nos deu uma descrição aproximada desses nossos antepassados. Eram totalmente cobertos de pelo, tinham barba, orelhas pontiagudas, viviam nas árvores e formavam manadas.

É de supor que, como conseqüência direta de seu gênero de vida, devido ao qual as mãos, ao trepar, tinham que desempenhar funções distintas das dos pés, esses macacos foram-se acostumando a prescindir de suas mãos ao caminhar pelo chão e começaram a adotar cada vez mais uma posição ereta. Foi o passo decisivo para a transição do macaco ao homem.

Todos os macacos antropomorfos que existem hoje podem permanecer em posição erecta e caminhar apoiando-se unicamente sobre seus pés; mas o fazem só em casos de extrema necessidade e, além disso, com enorme lentidão. Caminham habitualmente em atitude semi-erecta, e sua marcha inclui o uso das mãos. A maioria desses macacos apóiam no solo os dedos e, encolhendo as pernas, fazem avançar o corpo por entre os seus largos braços, como um paralítico que caminha com muletas. Em geral, podemos ainda hoje observar entre os macacos todas as formas de transição entre a marcha a quatro patas e a marcha em posição erecta. Mas para nenhum deles a posição erecta vai além de um recurso circunstancial.

E posto que a posição erecta havia de ser para os nossos peludos antepassados primeiro uma norma, e logo uma necessidade, dai se depreende que naquele período as mãos tinham que executar funções cada vez mais variadas. Mesmo entre os macacos existe já certa divisão de funções entre os pés e as mãos. Como assinalamos acima, enquanto trepavam as mãos eram utilizadas de maneira diferente que os pés. As mãos servem fundamentalmente para recolher e sustentar os alimentos, como o fazem já alguns mamíferos inferiores com suas patas dianteiras. Certos macacos recorrem às mãos para 
construir ninhos nas árvores; e alguns, como o chimpanzé, chegam a construir telhados entre os ramos, para defender-se das inclemências do tempo. A mão lhes serve para empunhar garrotes, com os quais se defendem de seus inimigos, ou para os bombardear com frutos e pedras. Quando se encontram prisioneiros realizam com as mãos várias operações que copiam dos homens. Mas aqui precisamente é que se percebe quanto é grande a distância que separa a mão primitiva dos macacos, inclusive os antropóides mais superiores, da mão do homem, aperfeiçoada pelo trabalho durante centenas de milhares de anos. O número e a disposição geral dos ossos e dos músculos são os mesmos no macaco e no homem, mas a mão do selvagem mais primitivo é capaz de executar centenas de operações que não podem ser realizadas pela mão de nenhum macaco. Nenhuma mão simiesa construiu jamais um machado de pedra, por mais tosco que fosse.

Por isso, as funções, para as quais nossos antepassados foram adaptando pouco a pouco suas mãos durante os muitos milhares de anos em que se prolongam o período de transição do macaco ao homem, só puderam ser, a princípio, funções sumamente simples. Os selvagens mais primitivos, inclusive aqueles nos quais se pode presumir o retorno a um estado mais próximo da animalidade, com uma degeneração física simultânea, são muito superiores àqueles seres do período de transição. Antes de a primeira lasca de sílex ter sido transformada em machado pela mão do homem, deve ter sido transcorrido um período de tempo tão largo que, em comparação com ele, o período histórico por nós conhecido torna-se insignificante. Mas já havia sido dado o passo decisivo: a mão era livre e podia agora adquirir cada vez mais destreza e habilidade; e essa maior flexibilidade adquirida transmitia-se por herança e aumentava de geração em geração.

Vemos, pois, que a mão não é apenas o órgão do trabalho; é também produto dele. Unicamente pelo trabalho, pela adaptação a novas e novas funções, pela transmissão hereditária do aperfeiçoamento especial assim adquirido pelos músculos e ligamentos e, num período mais amplo, também pelos ossos; unicamente pela aplicação sempre renovada dessas habilidades transmitidas a funções novas e cada vez mais complexas foi que a mão do homem atingiu esse grau de perfeição que pôde dar vida, como por artes de magia, aos quadros de Rafael, às estátuas de Thorwaldsen e à música de Paganini.

Mas a mão não era algo com existência própria e independente. Era unicamente um membro de um organismo íntegro e sumamente complexo. E o que beneficiava à mão beneficiava também a todo o corpo servido por ela; e o beneficiava em dois aspectos.

Primeiramente, em virtude da lei que Darwin chamou de correlação do crescimento. Segundo essa lei, certas formas das diferentes partes dos seres orgânicos sempre estão ligadas a determinadas formas de outras partes, que aparentemente não têm nenhuma relação com as primeiras. Assim, todos os animais que possuem glóbulos vermelhos sem núcleo e cujo occipital está articulado com a primeira vértebra por meio de dois côndilos, possuem, sem exceção, glândulas mamárias para a alimentação de suas crias. Assim também, a úngula fendida de alguns mamíferos está ligada de modo geral à presença de um estômago multilocular adaptado à ruminação. As modificações experimentadas por certas formas provocam mudanças na forma de outras partes do organismo, sem que estejamos em condições de explicar tal conexão. Os gatos totalmente brancos e de olhos azuis são sempre ou quase sempre surdos. O aperfeiçoamento gradual da mão do homem e a adaptação concomitante dos pés ao andar em posição erecta exerceram indubitavelmente, em virtude da referida correlação, certa influência sobre outras partes do organismo. Contudo, essa ação se acha ainda tão pouco estudada que aqui não podemos senão assinalá-la em termos gerais.

Muito mais importante é a ação direta - possível de ser demonstrada - exercida pelo desenvolvimento da mão sobre o resto do organismo. Como já dissemos, nossos 
antepassados simiescos eram animais que viviam em manadas; evidentemente, não é possível buscar a origem do homem, o mais social dos animais, em antepassados imediatos que não vivessem congregados. Em face de cada novo progresso, o domínio sobre a natureza, que tivera início com o desenvolvimento da mão, com o trabalho, ia ampliando os horizontes do homem, levando-o a descobrir constantemente nos objetos novas propriedades até então desconhecidas. Por outro lado, o desenvolvimento do trabalho, ao multiplicar os casos de ajuda mútua e de atividade conjunta, e ao mostrar assim as vantagens dessa atividade conjunta para cada indivíduo, tinha que contribuir forçosamente para agrupar ainda mais os membros da sociedade. Em resumo, os homens em formação chegaram a um ponto em que tiveram necessidade de dizer algo uns aos outros. A necessidade criou o órgão: a laringe pouco desenvolvida do macaco foi-se transformando, lenta mas firmemente, mediante modulações que produziam por sua vez modulações mais perfeitas, enquanto os órgãos da boca aprendiam pouco a pouco a pronunciar um som articulado após outro.

A comparação com os animais mostra-nos que essa explicação da origem da linguagem a partir do trabalho e pelo trabalho é a única acertada. O pouco que os animais, inclusive os mais desenvolvidos, têm que comunicar uns aos outros pode ser transmitido sem o concurso da palavra articulada. Nenhum animal em estado selvagem sente-se prejudicado por sua incapacidade de falar ou de compreender a linguagem humana. Mas a situação muda por completo quando o animal foi domesticado pelo homem. O contato com o homem desenvolveu no cão e no cavalo um ouvido tão sensível à linguagem articulada que esses animais podem, dentro dos limites de suas representações, chegar a compreender qualquer idioma. Além disso, podem chegar a adquirir sentimentos antes desconhecidos por eles, como o apego ao homem, o sentimento de gratidão, etc. Quem conheça bem esses animais dificilmente poderá escapar à convicção de que, em muitos casos, essa incapacidade de falar é experimentada agora por eles como um defeito. Desgraçadamente, esse defeito não tem remédio, pois os seus órgãos vocais se acham demasiado especializados em determinada direção. Contudo, quando existe um órgão apropriado, essa incapacidade pode ser superada dentro de certos limites. Os órgãos vocais das aves distinguem-se em forma radical dos do homem e, no entanto, as aves são os únicos animais que podem aprender a falar; e o animal de voz mais repulsiva, o papagaio, é o que melhor fala. E não importa que se nos objete dizendo-nos que o papagaio não sabe o que fala. Claro está que por gosto apenas de falar e por sociabilidade o papagaio pode estar horas e horas repetindo todo o seu vocabulário. Mas, dentro do marco de suas representações, pode chegar também a compreender o que diz. Ensinai a um papagaio dizer palavrões (uma das distrações favoritas dos marinheiros que regressam das zonas quentes) e vereis logo que se o irritardes ele fará uso desses palavrões com a mesma correção de qualquer verdureira de Berlim. E o mesmo ocorre com o pedido de gulodices.

Primeiro o trabalho, e depois dele e com ele a palavra articulada, foram os dois estímulos principais sob cuja influência o cérebro do macaco foi-se transformando gradualmente em cérebro humano - que, apesar de toda sua semelhança, supera-o consideravelmente em tamanho e em perfeição. E à medida em que se desenvolvia o cérebro, desenvolviam-se também seus instrumentos mais imediatos: os órgãos dos sentidos. Da mesma maneira que o desenvolvimento gradual da linguagem está necessariamente acompanhado do correspondente aperfeiçoamento do órgão do ouvido, assim também o desenvolvimento geral do cérebro está ligado ao aperfeiçoamento de todos os Órgãos dos sentidos. A vista da águia tem um alcance muito maior que a do homem, mas o olho humano percebe nas coisas muitos mais detalhes que o olho da águia. $\mathrm{O}$ cão tem um olfato muito mais fino que o do homem, mas não pode captar nem a centésima parte dos odores que servem ao homem como sinais para distinguir coisas diversas. E o sentido do tato, que o macaco possui a duras penas na forma mais tosca e primitiva, foi-se desenvolvendo unicamente 
com o desenvolvimento da própria mão do homem, através do trabalho.

O desenvolvimento do cérebro e dos sentidos a seu serviço, a crescente clareza de consciência, a capacidade de abstração e de discernimento cada vez maiores, reagiram por sua vez sobre o trabalho e a palavra, estimulando mais e mais o seu desenvolvimento. Quando o homem se separa definitivamente do macaco esse desenvolvimento não cessa de modo algum, mas continua, em grau diverso e em diferentes sentidos entre os diferentes povos e as diferentes épocas, interrompido mesmo às vezes por retrocessos de caráter local ou temporário, mas avançando em seu conjunto a grandes passos, consideravelmente impulsionado e, por sua vez, orientado em um determinado sentido por um novo elemento que surge com o aparecimento do homem acabado: a sociedade.

Foi necessário, seguramente, que transcorressem centenas de milhares de anos - que na história da Terra têm uma importância menor que um segundo na vida de um homem antes que a sociedade humana surgisse daquelas manadas de macacos que trepavam pelas árvores. Mas, afinal, surgiu. E que voltamos a encontrar como sinal distintivo entre a manada de macacos e a sociedade humana? Outra vez, o trabalho. A manada de macacos contentava-se em devorar os alimentos de uma área que as condições geográficas ou a resistência das manadas vizinhas determinavam. Transportava-se de um lugar para outro e travava lutas com outras manadas para conquistar novas zonas de alimentação; mas era incapaz de extrair dessas zonas mais do que aquilo que a natureza generosamente lhe oferecia, se excetuarmos a ação inconsciente da manada ao adubar o solo com seus excrementos. Quando foram ocupadas todas as zonas capazes de proporcionar alimento, o crescimento da população simiesca tornou-se já impossível; no melhor dos casos o número de seus animais mantinha-se no mesmo nível Mas todos os animais são uns grandes dissipadores de alimentos; além disso, com freqüência, destroem em germe a nova geração de reservas alimentícias. Diferentemente do caçador, o lobo não respeita a cabra montês que lhe proporcionaria cabritos no ano seguinte; as cabras da Grécia, que devoram os jovens arbustos antes de poder desenvolver-se, deixaram nuas todas as montanhas do pais. Essa "exploração rapace" levada a efeito pelos animais desempenha um grande papel na transformação gradual das espécies, ao obrigá-las a adaptar-se a alimentos que não são os habituais para elas, com o que muda a composição química de seu sangue e se modifica toda a constituição física do animal; as espécies já plasmadas desaparecem. Não há dúvida de que essa exploração rapace contribuiu em alto grau para a humanização de nossos antepassados, pois ampliou o número de plantas e as partes das plantas utilizadas na alimentação por aquela raça de macacos que superava todas as demais em inteligência e em capacidade de adaptação. Em uma palavra, a alimentação, cada vez mais variada, oferecia ao organismo novas e novas substâncias, com o que foram criadas as condições químicas para a transformação desses macacos em seres humanos. Mas tudo isso não era trabalho no verdadeiro sentido da palavra. O trabalho começa com a elaboração de instrumentos. E que representam os instrumentos mais antigos, a julgar pelos restos que nos chegaram dos homens préhistóricos, pelo gênero de vida dos povos mais antigos registrados pela história, assim como pelo dos selvagens atuais mais primitivos? São instrumentos de caça e de pesca, sendo os primeiros utilizados também como armas. Mas a caça e a pesca pressupõem a passagem da alimentação exclusivamente vegetal à alimentação mista, o que significa um novo passo de sua importância na transformação do macaco em homem. A alimentação cárnea ofereceu ao organismo, em forma quase acabada, os ingredientes mais essenciais para o seu metabolismo. Desse modo abreviou o processo da digestão e outros processos da vida vegetativa do organismo (isto é, os processos análogos ao da vida dos vegetais), poupando, assim, tempo, materiais e estímulos para que pudesse manifestar-se ativamente a vida propriamente animal. E quanto mais o homem em formação se afastava do reino vegetal, mais se elevava sobre os animais. Da mesma maneira que o hábito da alimentação mista converteu o gato e o cão selvagens em servidores do homem, assim 
também o hábito de combinar a carne com a alimentação vegetal contribuiu poderosamente para dar força física e independência ao homem em formação. Mas onde mais se manifestou a influência da dieta cárnea foi no cérebro, que recebeu assim em quantidade muito maior do que antes as substâncias necessárias à sua alimentação e desenvolvimento, com o que se foi tomando maior e mais rápido o seu aperfeiçoamento de geração em geração. Devemos reconhecer - e perdoem os senhores vegetarianos - que não foi sem ajuda da alimentação cárnea que o homem chegou a ser homem; e o fato de que, em uma ou outra época da história de todos os povos conhecidos, o emprego da carne na alimentação tenha chegado ao canibalismo (ainda no século $X$ os antepassados dos berlinenses, os veletabos e os viltses, devoravam os seus progenitores) é uma questão que não tem hoje para nós a menor importância.

O consumo de carne na alimentação significou dois novos avanços de importância decisiva: o uso do fogo e a domesticação dos animais. O primeiro reduziu ainda mais o processo da digestão, já que permitia levar a comida à boca, como se disséssemos, meio digerida; o segundo multiplicou as reservas de carne, pois agora, ao lado da caça, proporcionava uma nova fonte para obtê-la em forma mais regular. A domesticação de animais também proporcionou, com o leite e seus derivados, um novo alimento, que era pelo menos do mesmo valor que a carne quanto à composição. Assim, esses dois adiantamentos converteram-se diretamente para o homem em novos meios de emancipação. Não podemos deter-nos aqui em examinar minuciosamente suas conseqüências.

O homem, que havia aprendido a comer tudo o que era comestível, aprendeu também, da mesma maneira, a viver em qualquer clima. Estendeu-se por toda a superfície habitável da Terra, sendo o único animal capaz de fazê-lo por iniciativa própria. Os demais animais que se adaptaram a todos os climas — os animais domésticos e os insetos parasitas - não o conseguiram por si, mas unicamente acompanhando o homem. E a passagem do clima uniformemente cálido da pátria original para zonas mais frias, onde o ano se dividia em verão e inverno, criou novas exigências, ao obrigar o homem a procurar habitação e a cobrir seu corpo para proteger-se do frio e da umidade. Surgiram assim novas esferas de trabalho, e com elas novas atividades, que afastaram ainda mais o homem dos animais.

Graças à cooperação da mão, dos órgãos da linguagem e do cérebro, não só em cada indivíduo, mas também na sociedade, os homens foram aprendendo a executar operações cada vez mais complexas, a propor-se e alcançar objetivos cada vez mais elevados. $O$ trabalho mesmo se diversificava e aperfeiçoava de geração em geração, estendendo-se cada vez a novas atividades. A caça e à pesca veio juntar-se a agricultura, e mais tarde a fiação e a tecelagem, a elaboração de metais, a olaria e a navegação. Ao lado do comércio e dos ofícios apareceram, finalmente, as artes e as ciências; das tribos saíram as nações e os Estados. Apareceram o direito e a política, e com eles o reflexo fantástico das coisas no cérebro do homem: a religião. Frente a todas essas criações, que se manifestavam em primeiro lugar como produtos do cérebro e pareciam dominar as sociedades humanas, as produções mais modestas, fruto do trabalho da mão, ficaram relegadas a segundo plano, tanto mais quanto numa fase muito recuada do desenvolvimento da sociedade (por exemplo, já na família primitiva), a cabeça que planejava o trabalho já era capaz de obrigar mãos alheias a realizar o trabalho projetado por ela. O rápido progresso da civilização foi atribuído exclusivamente à cabeça, ao desenvolvimento e à atividade do cérebro. Os homens acostumaram-se a explicar seus atos pelos seus pensamentos, em lugar de procurar essa explicação em suas necessidades (refletidas, naturalmente, na cabeça do homem, que assim adquire consciência delas). Foi assim que, com o transcurso do tempo, surgiu essa concepção idealista do mundo que dominou o cérebro dos homens, sobretudo a partir do desaparecimento do mundo antigo, e continua ainda a dominá-lo, a tal ponto que mesmo os naturalistas da escola darwiniana mais chegados ao materialismo são 
ainda incapazes de formar uma idéia clara acerca da origem do homem, pois essa mesma influência idealista lhes impede de ver o papel desempenhado aqui pelo trabalho.

Os animais, como já indicamos de passagem, também modificam com sua atividade a natureza exterior, embora não no mesmo grau que o homem; e essas modificações provocadas por eles no meio ambiente repercutem, como vimos, em seus causadores, modificando-os por sua vez. Nada ocorre na natureza em forma isolada. Cada fenômeno afeta a outro, e é por seu turno influenciado por este; e é em geral o es. esquecimento desse movimento e dessa interação universal o que impede a nossos naturalistas perceber com clareza as coisas mais simples. Já vimos como as cabras impediram o reflorestamento dos bosques na Grécia; em Santa Helena, as cabras e os porcos desembarcados pelos primeiros navegantes chegados à ilha exterminaram quase por completo a vegetação ali existente, com o que prepararam o terreno para que pudessem multiplicar-se as plantas levadas mais tarde por outros navegantes e colonizadores. Mas a influência duradoura dos animais sobre a natureza que os rodeia é inteiramente involuntária e constitui, no que se refere aos animais, um fato acidental. Mas, quanto mais os homens se afastam dos animais, mais sua influência sobre a natureza adquire um caráter de uma ação intencional e planejada, cujo fim é alcançar objetivos projetados de antemão. Os animais destroçam a vegetação do lugar sem dar-se conta do que fazem. Os homens, em troca, quando destroem a vegetação o fazem com o fim de utilizar a superfície que fica livre para semear trigo, plantar árvores ou cultivar a videira, conscientes de que a colheita que irão obter superará várias vezes o semeado por eles. O homem traslada de um pais para outro plantas úteis e animais domésticos, modificando assim a flora e a fauna de continentes inteiros. Mais ainda: as plantas e os animais, cultivadas aquelas e criados estes em condições artificiais, sofrem tal influência da mão do homem que se tornam irreconhecíveis.

Não foram até hoje encontrados os antepassados silvestres de nossos cultivos cerealistas. Ainda não foi resolvida a questão de saber qual o animal que deu origem aos nossos cães atuais, tão diferentes uns de outros, ou às atuais raças de cavalos, também tão numerosos. Ademais, compreende-se de logo que não temos a intenção de negar aos animais a faculdade de atuar em forma planificada, de um modo premeditado. Ao contrário, a ação planificada existe em germe onde quer que o protoplasma - a albumina viva - exista e reaja, isto é, realize determinados movimentos, embora sejam os mais simples, em resposta a determinados estímulos do exterior. Essa reação se produz, não digamos já na célula nervosa, mas inclusive quando ainda não há célula de nenhuma espécie. $\mathrm{O}$ ato pelo qual as plantas insetívoras se apoderam de sua presa aparece também, até certo ponto, como um ato planejado, embora se realize de um modo totalmente inconsciente. A possibilidade de realizar atos conscientes e premeditados desenvolve-se nos animais em correspondência com o desenvolvimento do sistema nervoso e adquire já nos mamíferos um nível bastante elevado. Durante as caçadas organizadas na Inglaterra pode-se observar sempre a infalibilidade com que a raposa utiliza seu perfeito conhecimento do lugar para ocultar-se aos seus perseguidores, e como conhece e sabe aproveitar muito bem todas as vantagens do terreno para despistá-los. Entre nossos animais domésticos, que chegaram a um grau mais alto de desenvolvimento graças à sua convivência com o homem podem ser observados diariamente atos de astúcia, equiparáveis aos das crianças, pois do mesmo modo que o desenvolvimento do embrião humano no ventre materno é uma réplica abreviada de toda a história do desenvolvimento físico seguido através de milhões de anos pelos nossos antepassados do reino animal, a partir do estado larval, assim também o desenvolvimento espiritual da criança representa uma réplica, ainda mais abreviada, do desenvolvimento intelctual desses mesmos antepassados, pelo menos dos mais próximos. Mas nem um só ato planificado de nenhum animal pôde imprimir na natureza o selo de sua vontade. Só o homem pôde fazê-lo. 
Resumindo: só o que podem fazer os animais é utilizar a natureza e modificá-la pelo mero fato de sua presença nela. $O$ homem, ao contrário, modifica a natureza e a obriga a servirIhe, domina-a. E ai está, em última análise, a diferença essencial entre o homem e os demais animais, diferença que, mais uma vez, resulta do trabalho.

Contudo, não nos deixemos dominar pelo entusiasmo em face de nossas vitórias sobre a natureza. Após cada uma dessas vitórias a natureza adota sua vingança. É verdade que as primeiras conseqüências dessas vitórias são as previstas por nós, mas em segundo e em terceiro lugar aparecem conseqüências muito diversas, totalmente imprevistas e que, com freqüência, anulam as primeiras. Os homens que na Mesopotâmia, na Grécia, na Ásia Menor e outras regiões devastavam os bosques para obter terra de cultivo nem sequer podiam imaginar que, eliminando com os bosques os centros de acumulação e reserva de umidade, estavam assentando as bases da atual aridez dessas terras. Os italianos dos Alpes, que destruíram nas encostas meridionais os bosques de pinheiros, conservados com tanto carinho nas encostas setentrionais, não tinham idéia de que com isso destruíam as raízes da indústria de laticínios em sua região; e muito menos podiam prever que, procedendo desse modo, deixavam a maior parte do ano secas as suas fontes de montanha, com o que Ihes permitiam, chegado o período das chuvas, despejar com maior fúria suas torrentes sobre a planície. Os que difundiram o cultivo da batata na Europa não sabiam que com esse tubérculo farináceo difundiam por sua vez a escrofulose. Assim, a cada passo, os fatos recordam que nosso domínio sobre a natureza não se parece em nada com o domínio de um conquistador sobre o povo conquistado, que não é o domínio de alguém situado fora da natureza, mas que nós, por nossa carne, nosso sangue e nosso cérebro, pertencemos à natureza, encontramo-nos em seu seio, e todo o nosso domínio sobre ela consiste em que, diferentemente dos demais seres, somos capazes de conhecer suas leis e aplicá-las de maneira adequada.

Com efeito, aprendemos cada dia a compreender melhor as leis da natureza e a conhecer tanto os efeitos imediatos como as conseqüências remotas de nossa intromissão no curso natural de seu desenvolvimento. Sobretudo depois dos grandes progressos alcançados neste século pelas ciências naturais, estamos em condições de prever e, portanto, de controlar cada vez melhor as remotas conseqüências naturais de nossos atos na produção, pelo menos dos mais correntes. E quanto mais isso seja uma realidade, mais os homens sentirão e compreenderão sua unidade com a natureza, e mais inconcebível será essa idéia absurda e antinatural da antítese entre o espírito e a matéria, o homem e a natureza, a alma e o corpo, idéia que começa a difundir-se pela Europa sobre a base da decadência da antigüidade clássica e que adquire seu máximo desenvolvimento no cristianismo.

Mas, se foram necessários milhares de anos para que o homem aprendesse, em certo grau, a prever as remotas conseqüências naturais no sentido da produção, muito mais the custou aprender a calcular as remotas conseqüências sociais desses mesmos atos. Falamos acima da batata e de seus efeitos quanto à difusão da escrofulose. Mas que importância pode ter a escrofulose, comparada com os resultados que teve a redução da alimentação dos trabalhadores a batatas puramente sobre as condições de vida das massas do povo de países inteiros, com a fome que se estendeu em 1847 pela Irlanda em conseqüência de uma doença provocada por esse tubérculo e que levou à sepultura um milhão de irlandeses que se alimentavam exclusivamente, ou quase exclusivamente, de batatas e obrigou a que emigrassem para além-mar outros dois milhões? Quando os árabes aprenderam a distilar o álcool, nem sequer ocorreu-lhes pensar que haviam criado uma das armas principais com que iria ser exterminada a população indígena do continente americano, então ainda desconhecido. E quando mais tarde Colombo descobriu a América não sabia que ao mesmo tempo dava nova vida à escravidão, há muito tempo desaparecida na Europa, e assentado as bases do tráfico dos negros. Os homens que nos 
séculos XVII e XVIII haviam trabalhado para criar a máquina a vapor não suspeitavam de que estavam criando um instrumento que, mais do que nenhum outro, haveria de subverter as condições sociais em todo o mundo e que, sobretudo na Europa, ao concentrar a riqueza nas mãos de uma minoria e ao privar de toda propriedade a imensa maioria da população, haveria de proporcionar primeiro o domínio social e político à burguesia, e provocar depois a luta de classe entre a burguesia e o proletariado, luta que só pode terminar com a liquidação da burguesia e a abolição de todos os antagonismos de classe. Mas também aqui, aproveitando uma experiência ampla, e às vezes cruel, confrontando e analisando os materiais proporcionados pela história, vamos aprendendo pouco a pouco a conhecer as conseqüências sociais indiretas e mais remotas de nossos atos na produção, o que nos permite estender também a essas conseqüências o nosso domínio e o nosso controle.

Contudo, para levar a termo esse controle é necessário algo mais do que o simples conhecimento. É necessária uma revolução que transforme por completo o modo de produção existente até hoje e, com ele, a ordem social vigente.

Todos os modos de produção que existiram até o presente só procuravam o efeito útil do trabalho em sua forma mais direta e Imediata. Não faziam o menor caso das conseqüências remotas, que só surgem mais tarde e cujos efeitos se manifestam unicamente graças a um processo de repetição e acumulação gradual. A primitiva propriedade comunal da terra correspondia, por um lado, a um estádio de desenvolvimento dos homens no qual seu horizonte era limitado, em geral, às coisas mais imediatas, e pressupunha, por outro lado, certo excedente de terras livres, que oferecia determinada margem para neutralizar os possíveis resultados adversos dessa economia primitiva. Ao esgotar-se o excedente de terras livres, começou a decadência da propriedade comunal. Todas as formas mais elevadas de produção que vieram depois conduziram à divisão da população em classes diferentes e, portanto, no antagonismo entre as classes dominantes e as classes oprimidas. Em conseqüência, os interesses das classes dominantes converteram-se no elemento propulsor da produção, enquanto esta não se limitava a manter, bem ou mal, a mísera existência dos oprimidos.

Isso encontra sua expressão mais acabada no modo de produção capitalista, que prevalece hoje na Europa ocidental. Os capitalistas individuais, que dominam a produção e a troca, só podem ocupar-se da utilidade mais imediata de seus atos. Mais ainda: mesmo essa utilidade - porquanto se trata da utilidade da mercadoria produzida ou trocada passa inteiramente ao segundo plano, aparecendo como único incentivo o lucro obtido na venda.

A ciência social da burguesia, a economia política clássica, só se ocupa preferentemente daquelas conseqüências sociais que constituem o objetivo imediato dos atos realizados pelos homens na produção e na troca. Isso corresponde plenamente ao regime social cuja expressão teórica é essa ciência. Porquanto os capitalistas isolados produzem ou trocam com o único fim de obter lucros imediatos, só podem ser levados em conta, primeiramente, os resultados mais próximos e mais imediatos. Quando um industrial ou um comerciante vende a mercadoria produzida ou comprada por ele e obtém o lucro habitual, dá-se por satisfeito e não lhe interessa de maneira alguma o que possa ocorrer depois com essa mercadoria e seu comprador. O mesmo se verifica com as conseqüências naturais dessas mesmas ações. Quando, em Cuba, os plantadores espanhóis queimavam os bosques nas encostas das montanhas para obter com a cinza um adubo que só lhes permitia fertilizar uma geração de cafeeiros de alto rendimento pouco lhes importava que as chuvas torrenciais dos trópicos varressem a camada vegetal do solo, privada da proteção das 
O PAPEL DO TRABALHO NA TRANSFORMAÇÃO DO MACACO EM HOMEM Página 9 de 9

arvores, e não deixassem depois de si senão rochas desnudas! Com o atual modo de produção, e no que se refere tanto às conseqüências naturais como às conseqüência sociais dos atos realizados pelos homens, o que interessa prioritariamente são apenas os primeiros resultados, os mais palpáveis. E logo até se manifesta estranheza pelo fato de as conseqüências remotas das ações que perseguiam esses fins serem multo diferentes e, na maioria dos casos, até diametralmente opostas; de a harmonia entre a oferta e a procura converter-se em seu antípoda, como nos demonstra o curso de cada um desses ciclos industriais de dez anos, e como puderam convencer-se disso os que com o "crack" viveram na Alemanha um pequeno prelúdio; de a propriedade privada baseada no trabalho próprio converter-se necessariamente, ao desenvolver-se, na ausência de posse de toda propriedade pelos trabalhadores, enquanto toda a riqueza se concentra mais e mais nas mãos dos que não trabalham; de [...] (2)

* Disponível em

http://www.marxists.org/portugues/marx/1876/otrabalhonatransformacaodomacacoemhome

Notas:

(1) Notas Sir William Thomson. grande autoridade na matéria, calculou em pouco mais de cem milhões de anos o tempo transcorrido desde o momento em que a Terra se esfriou o suficiente para que nela pudessem viver as plantas e os animais.

(Nota de Engels) Engels refere-se à crise econômica de 1873/1874. (N. da R)

(2) Aqui se interrompe o manuscrito. (N. da R.)

volta 